\title{
Berberine affects osteosarcoma via downregulating the caspase-1/IL-1ß signaling axis
}

\author{
HAO JIN, XIN JIN, BORAN CAO and WENBO WANG \\ Department of Orthopaedics, The First Affiliated Hospital of Harbin Medical University, \\ Harbin, Heilongjiang 150001, P.R. China
}

Received July 19, 2016; Accepted December 7, 2016

DOI: $10.3892 /$ or.2016.5327

\begin{abstract}
Osteosarcoma is one of the most devastating cancers with associated poor prognosis. Chronic bone inflammation frequently predisposes to tumorigenesis and progression of osteosarcoma. In the tumor inflammatory microenvironment, caspase-1 and its processed cytokines such as interleukin $1 \beta$ (IL-1 $\beta$ ) play an important role in the occurrence and development of cancer. Berberine is an isoquinoline alkaloid extracted from the dry root of Coptidis Rhizoma, which has been found to exhibit significant anticancer effects on a wide spectrum of carcinomas including osteosarcoma. However, the mechanisms underlying the anticancer effects of berberine in osteosarcoma remain poorly understood and their elucidation is critical for developing improved therapies. In the present study, we investigated the potential mechanism underlying the anticancer effect of berberine in osteosarcoma. We found that the expression of caspase- 1 and its downstream target IL-1 $\beta$ were higher in osteosarcoma cells compared with normal cells both in vitro and in vivo. Furthermore, administration of berberine is capable of reducing the expression of caspase- 1 and IL-1 $\beta$ in osteosarcoma cells and inhibiting the growth of tumor cells. Based on the above, for the first time, we propose the hyposis that berberine could gengerate an antiosteosarcoma property through downregulating caspase-1/ IL-1 $\beta$ inflammatory signaling axis.
\end{abstract}

\section{Introduction}

Osteosarcoma is the most prevalent aggressive malignant bone tumor arising from primitive transformed cells of mesenchymal origin in children and young adults (1). Osteosarcomas tend to occur at the sites of bone growth, presumably due to the proliferation of osteoblastic cells prone

Correspondence to: Dr Wenbo Wang, Department of Orthopaedics, The First Affiliated Hospital of Harbin Medical University, No. 23 Youzheng Road, Harbin, Heilongjiang 150001, P.R. China E-mail: 280798492@qq.com

Key words: berberine, osteosarcoma, caspase-1, IL-1 $\beta$ to acquire more osteosarcoma mutations which could lead to carcinomatous change of cells (2). In the present study, the treatment therapies of osteosarcoma was mainly performed by surgery combined with chemotherapy due to its relatively resistance to radiotherapy. However, the application of tumor chemotherapy drugs have many adverse effects and tumor cells are prone to acquire drug resistance $(3,4)$. Thus, to find a low toxicity, high efficiency anticancer drugs from natural compounds in the treatment of osteosarcoma has important significance.

The tumor microenvironment is commonly considered as an obligatory and significant component of almost all types of cancer, and the cells infiltrating such microenvironment are a source of inflammatory cytokines. Cytokines like IL-1 $\beta$ plays a key role in regulating inflammation during the development and progression of cancer (5). The IL-1 $\beta$ have pleiotropic effects on various carcinoma cells in the tumor microenvironment, particularly being capable of regulating pro-oncogenic transcription factors STAT3 and NF- $\kappa \mathrm{B}(6)$. Therefore, to reveal the IL-1 $\beta$ involved, inflammation related mechanisms are vitally important for the treatment of osteosarcoma.

Caspase-1 is a kind of cysteine protease that proteolytically cleaves other proteins, such as the precursor forms of the inflammatory cytokines IL-1 $\beta$, into active mature peptides. Consequently, IL-1 $\beta$ activate its downstream NF- $\kappa \mathrm{B}$ signaling and thus, enhance the release of inflammatory cytokines (7). Caspase- 1 and IL-1 $\beta$ have been shown to play important roles in inflammation, necrosis and pyroptosis, and may function in various developmental stages (8-11). Our preliminary experiments found that the expression of caspase- 1 was higher in osteosarcoma tissues than normal bone tissues. However, to the best of our knowledge, the role of caspase-1 and its downstrem target IL-1 $\beta$ in osteosarcoma have not been clarified.

Berberine was derived from traditional Chinese medicinal herbs which have drawn extensive attention towards its antineoplastic effects. It has been reported to suppress growth of a wide variety of tumor cells, including osteosarcoma, breast cancer and gastric carcinoma (12-15). Berberine potently inhibits osteosarcoma growth and metastasis as reported in a previous extensive study and the underlying mechanism is controversial and not that obscure $(16,17)$. Therefore, development of effective therapeutic strategies based on a better understanding of the molecular mechanisms underlying the anti-osteosarcoma property of berberine is urgently needed. 
In the present research, we studied the effects of berberine on osteosarcoma cells in vivo and in vitro. Our data provided mechanistic insight into the role of berberine in inhibition of osteosarcoma cell growth via downregulating caspase-1/IL-1 $\beta$ inflammatory signaling pathway.

\section{Materials and methods}

Cell culture and treatment. Human Saos-2 and MG-63 cell lines were obtained from the American Type Culture Collection (ATCC; Manassas, VA, USA). Berberine was purchased from Sigma-Aldrich (St. Louis, MO, USA). Cells were cultured in Dulbecco's modified Eagle's medium (DMEM; HyClone Laboratories, Inc., Logan, UT, USA) supplemented with $10 \%$ (v/v) fetal bovine serum (FBS; Gibco, Carlsbad, CA, USA) in an atmosphere of $95 \%$ humidified air and $5 \% \mathrm{CO}_{2}$ at $37^{\circ} \mathrm{C}$. Cells were investigated within $8 \mathrm{~h}$ of harvest. To detect the effects of berberine on osteosarcoma, cells were treated without or with berberine (Sigma-Aldrich), respectively. To detect the effects of caspase-1 on osteosarcoma, cells were treated without or with selective caspase-1 inhibitor N-Ac-TyrVal-Ala-Asp-CMK (Ac-YVAD-CMK) (Cayman Chemical, Ann Arbor, MI, USA), respectively.

MTT assay of cell proliferation. Cell viability was determined by MTT assay according to the manufacturer's instructions. Briefly, cells $\left(2 \times 10^{4}\right.$ cells/well) were seeded in a 96 -well plate and treated differently based on the experimental purpose. Cells were washed with phosphate-buffered saline (PBS), and then $20 \mu \mathrm{l}$ of MTT (3-(4,5-dimethylthiazol-2-yl)-2,5-diphenyl tetrazolium bromide solution $(5 \mathrm{mg} / \mathrm{ml})$ was added to each well. The plate was covered and shaken at room temperature, after which the medium was discarded. Next, dimethyl sulfoxide (DMSO) was added to each well $(200 \mu \mathrm{l})$, and the solution was vigorously mixed to dissolve the purple tetrazolium crystals. The amount of produced purple formazan is proportional to the percentage of cell viability. The absorbance of each well was measured by automated microplate reader at a test wavelength of $490 \mathrm{~nm}$. All experiments were repeated at least three times.

Western blot analysis. Western blotting was used to detect the expression levels of the proteins of interest. Drugs were diluted and added to cells for $24 \mathrm{~h}$ at $37^{\circ} \mathrm{C}$ before analysis by western blot. The cells were washed using ice-cold phosphate-buffered saline, and total protein was harvested with radioimmunoprecipitation assay buffer (RIPA) containing $1 \%$ protease inhibitor (Sigma-Aldrich). Protein $(100 \mu \mathrm{g})$ per sample was separated using $12 \%$ SDS-PAGE, and then transferred into nitrocellulose membranes. The membrane was blocked with 5\% non-fat milk (BD Biosciences, San Jose, CA, USA) and $0.1 \%$ Tween-20 in Tris-buffered saline and immunoblotted overnight using appropriate primary antibodies at $4^{\circ} \mathrm{C}$ with gentle shaking. After that, fluorochrome labelled secondary antibody (Alexa Fluor 800; LI-COR Biosciences, Lincoln, NE, USA) was used to identify the appropriate primary antibody. Immunoreactivity was detected with the Odyssey fluorescent scanning system (LI-COR Biosciences) and analyzed by Image Studio software. $\beta$-actin was used as a loading control.
cDNA synthesis and real-time PCR analysis. Real-time PCR was used to measure caspase- 1 and IL-1 $\beta$ mRNA levels. Total RNA was extracted using TRIzol reagent (Invitrogen, Carlsbad, CA, USA) from tissues and cells. First-strand cDNA was synthesized using a reverse transcriptase kit (Applied Biosystems, Foster City, CA, USA) according to the manufacturer's instructions. Real-time PCRs were carried out with a SYBR-Green PCR Master Mix kit (Applied Biosystems) and performed on 7500 FAST Real-Time PCR system (Applied Biosystems, Carlsbad, CA, USA). GAPDH was used as an internal control. The following primers were used in the study. Caspase-1: forward, 5'-ACACGTCTTGCCCTCATTATCT-3' and reverse, 5'-ATAACCTTGGGCTTGTCTTTCA-3'; IL-1 $\beta$ : forward, 5'-CCCTGCAGCTGGAGAGTGTGG-3' and reverse, 5'-TGTGCTCTGCTTGAGAGGTGCT-3'; GAPDH: forward, 5'-ATCACTGCCACCCAGAAGAC3' and reverse, 5'-TTTCT AGACGGCAGGTCAGG-3'.

TUNEL assay. Cells were seeded on coverslips in 6-well culture plates and grown overnight for adherence, then treated with different drugs, respectively. Apoptosis was measured by an In Situ Cell Death Detection kit according to the manufacturer's instructions (Roche Applied Science). In brief, cells were fixed with freshly prepared $4 \%$ paraformaldehyde for $60 \mathrm{~min}$. The slides were rinsed with PBS and incubated in $0.1 \%$ Triton X-100 permeabilization solution for $2 \mathrm{~min}$. Then slides were incubated with TUNEL reaction mixture for $60 \mathrm{~min}$ at $37^{\circ} \mathrm{C}$ in a humidified chamber. the rinsed slides were counterstained with DAPI. Cells were counted under a fluorescence microscopy and the green fluorescence staining cells were calculated as positive-staining cells. All experiments were repeated at least three times.

Establishment of a xenograft mouse model. The experimental protocols were approved by the Ethic Committee of Harbin Medical University (Harbin, China). The use of animals followed the National Institutes of Health guide for the care and use of laboratory animals published by the US National Institutes of Health (NIH Publication no. 85-23, revised 1996). BALB/c-nu/nu mice, male, 5-6-week old weighing 18-20 $\mathrm{g}$ were used. The mice were housed with a regular 12-h light/12-h dark cycle and ad libitum access to standard rodent chow diet and were kept in a pathogen-free environment. For in vivo tracking, the Saos-2 and MG-63 cells were stably transfected with firefly luciferase. Saos-2 and MG-63 cells ( $1 \times 10^{7}$ cells were suspended in $100 \mu 1$ serum-free DMEM) were injected subcutaneously into the back of mice. Eight days post-implantation, the mice were randomly divided into three groups ( $\mathrm{n}=6$ for each group) and fed by oral gavage with saline, berberine $(20 \mathrm{mg} / \mathrm{kg} / \mathrm{day})$, or berberine and intraperitoneal caspase-1 inhibitor Ac-Y VAD-CHO (0.1 mg/kg/day). Tumor growth was monitored by luciferase activity in Saos-2 and MG-63 cells, and the emitted photons from the target site penetrated through the mammalian tissue and could be externally detected and quantified using a sensitive light imaging system. Mice were euthanized 21 days after treatment and the tumors were isolated for further detection.

Statistical analysis. Data are expressed as mean \pm standard error of mean (mean \pm SEM) and analyzed with SPSS 13.0 

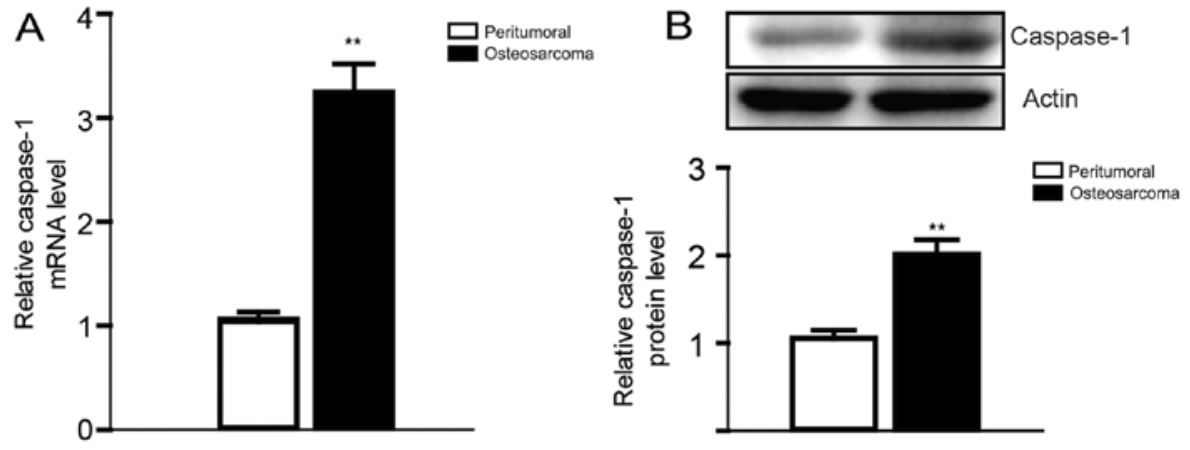

Figure 1. The mRNA and protein expression of caspase-1 were both elevated in six pairs of osteosarcoma tissues compared with peritumoral tissues (A) Caspase-1 mRNA expression in osteosarcoma tissues was obviously highter than that in peritumorial tissues as determined by real-time PCR. (B) Caspase-1 protein expression in osteosarcoma tissues was obviously highter than that in peritumorial tissues as determined by western blotting. Data are expressed as mean \pm SEM. $n=3$. ** $\mathrm{P}<0.01$ when compared with peritumoral control group.
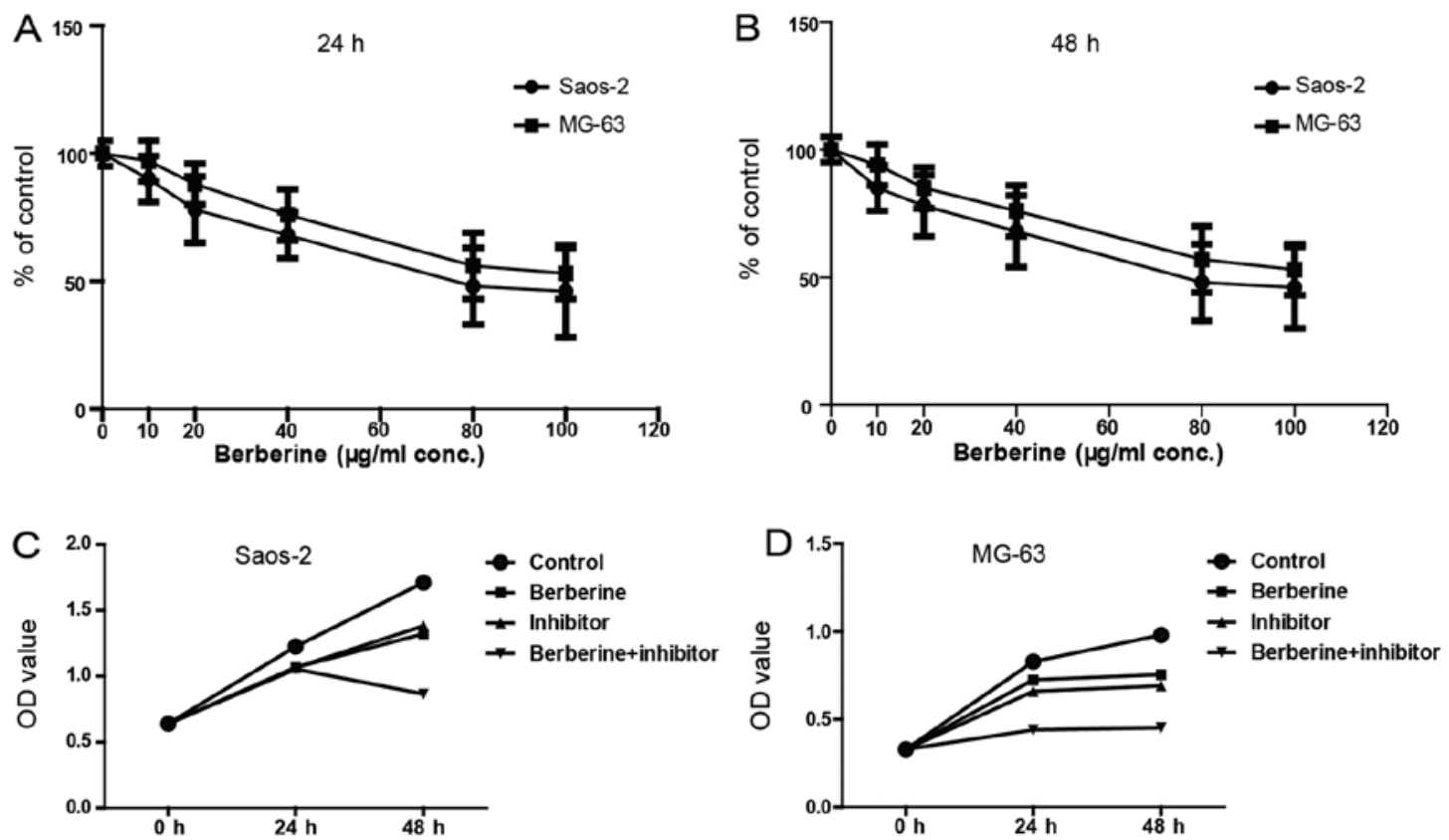

Figure 2. The effects of berberine and caspase-1 inhibitor on the viability of Saos-2 and MG-63 osteosarcoma cells. (A and B) The viability of cells after treatment of different concentration of berberine for 24 and $48 \mathrm{~h}$, respectively. (C and D) The viability of cells after administration of berberine ( $80 \mu \mathrm{M})$ and/or caspase-1 inhibitor, $\mathrm{n}=6 .{ }^{*} \mathrm{P}<0.05$ when compared with control group.

software. Statistical comparisons between the two groups were performed using the Student's t-test. Statistical comparisons among multiple groups were performed using analysis of variance (ANOVA). A two-tailed $\mathrm{P}<0.05$ was taken to indicate a statistically significant difference.

\section{Results}

The expression of caspase-1 in osteosarcoma tissues. Based on previous studies on the relationship between osteosarcoma and inflammation, and the central role of caspase- 1 in the process of inflammation (18-20), we first compared the expression level of caspase-1 in osteosarcoma tissues from six pairs of clinical osteosarcoma cases with peritumoral tissues. Then we found that the expression of caspase-1 was obviously elevated both in the mRNA and the protein level, which is consistent to our expectation (Fig. 1).
Berberine decreases the viability of osteosarcoma cell. Next, we evaluated the effects of berberine on Saos-2 and MG-63 cells by MTT assay. MTT assay results demonstrated that berberine significantly inhibits the growth of Saos- 2 and MG-63 cells in a time- and dose-dependent manner. As shown in Fig. 2A and B, the concentration of berberine at $80 \mu \mathrm{M}$ could inhibit the cell viability to the greatest extent; and the viable cells at $48 \mathrm{~h}$ decreased more obviously than $24 \mathrm{~h}$ after treatment with $80 \mu \mathrm{M}$ berberine. Thus, the following administration of berberine were all at $48 \mathrm{~h}$ with $80 \mu \mathrm{M}$. Fig. $2 \mathrm{C}$ and D shows that berberine significantly reduced osteosarcoma cell viability and caspase-1 inhibitor exerts similar effects, which suggest that caspase-1 may be involved in the inhibition of osteosarcoma cell growth caused by berberine.

Berberine induces apoptosis of Saos-2 and MG-63 osteosarcoma cells. To study the effect of berberine administration on 

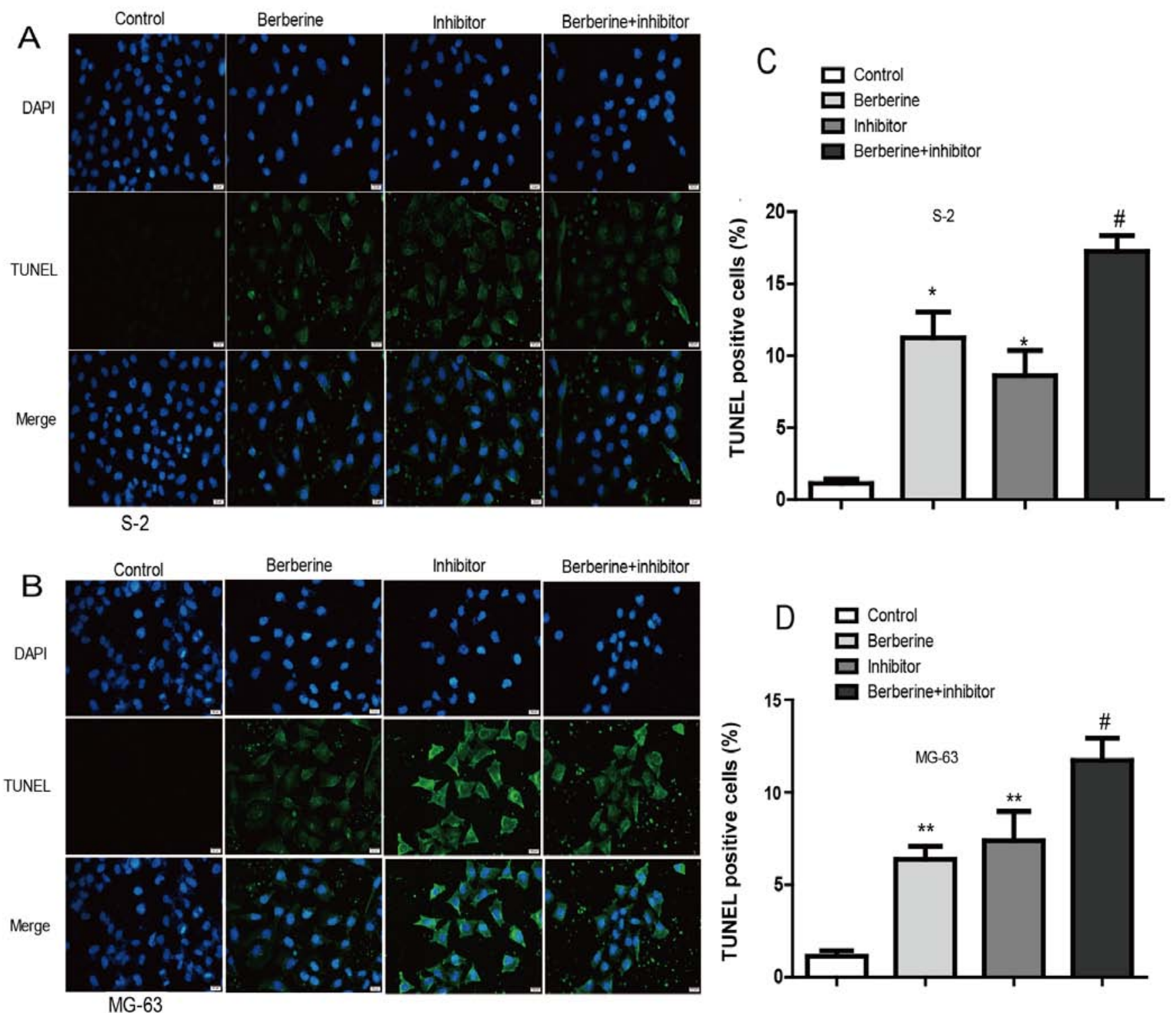

Figure 3. The anti-inflammation effect of berberine induced osteosarcoma apoptosis assessed using TUNEL staining. (A and C) Representative images of TUNEL-positive nuclei in green fluorescent color and total nuclei staining with propidium iodide (PI); (B and D) bar diagram showing the relative proportion of TUNEL-positive cells $(\mathrm{n}=6)$. ${ }^{*} \mathrm{P}<0.05$ vs. control, ${ }^{* *} \mathrm{P}<0.01$ when compared with control group; ${ }^{*} \mathrm{P}<0.05$ vs. berberine group.

osteosarcoma cell apoptosis, TUNEL assay was performed. Cells in the images with green nuclei were considered apoptotic. In Fig. 3, we found few cells with nuclei staining green in the control group. After being exposed to $80 \mu \mathrm{M}$ berberine for $48 \mathrm{~h}, \sim 13.12 \%$ of cells showed apoptotic hallmarks. Moreover, caspase-1 inhibitor exert similar effect to berberine. In addition, co-incubation berberine with caspase-1 inhibitor exerted inhibitory effects to the greatest extent. Thus, these results indicated that berberine could induce apoptosis of osteosarcoma cells possibly by caspase-1 involved process.

Berberine exerts anti-osteosarcoma property through reducing caspase-1 and IL-1 $\beta$ expression. Currently, the role of inflammation in cancers has caused widespread concern. It is believed that inflammation could promote the occurrence and development of cancer $(21,22)$. Real-time PCR and western blot assay was performed to explore the molecular mechanism of berberine on the anti-osteosarcoma property. As we can see from the bar graphs (Figs. 4 and 5), caspase-1 mRNA and protein expression level were both downregulated in Saos-2 and MG-63 osteosarcoma cells after treated with berberine; caspase-1 inhibition extert similar effect to berberine on caspase- 1 expression level. At the same time, to gain further insights into the mechanism of anti-osteosarcoma of berberine, we analyzed the expression level of caspase-1 downstream target IL-1 $\beta$, which plays a decisive role in the formation of tumor inflammatory microenvironment. The results show that the expression of IL-1 $\beta$ was consistent with caspase-1. Furthmore, immunofluorescence staining analysis was used to further confirm the anti-osteosarcoma property of berberine. Accordingly, immunofluorescence results showed that the expression of caspase- 1 and IL- $1 \beta$ were both downregulated compared with normal groups. Caspase-1 inhibition exterts similar effect to berberine on osteosarcoma cells (Fig. 6). 

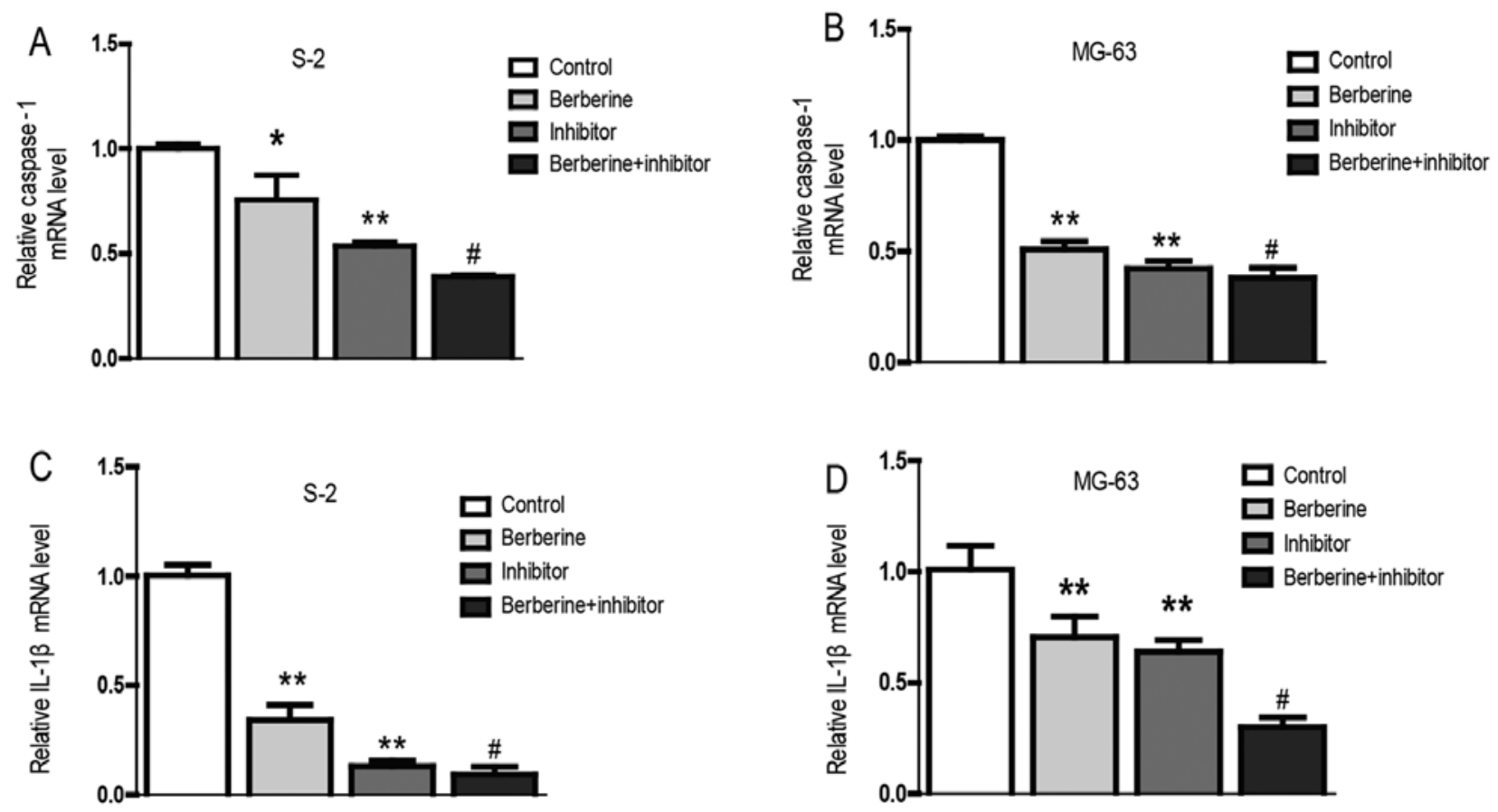

Figure 4. The effects of berberine and/or caspase-1 inhibitor on the mRNA expression level of caspase-1 and IL-1 $\beta$. After administration of berberine ( $80 \mu \mathrm{M})$ and/or caspase-1 inhibitor for $48 \mathrm{~h}$, the mRNA expression level was detected by real-time PCR. (A) Caspase-1 mRNA expression in the Saos-2 osteosarcoma cells. (B) Caspase-1 mRNA expression in the MG-63 osteosarcoma cells. (C) IL-1 $\beta$ mRNA expression in the Saos-2 osteosarcoma cells. (D) IL-1 $\beta$ mRNA expression in the MG-63 osteosarcoma cells. GAPDH served as an internal control. Data are expressed as mean \pm SEM. $n=3$. ${ }^{*} \mathrm{P}<0.05$ vs. control, ${ }^{* *} \mathrm{P}<0.01 \mathrm{vs}$. control. ${ }^{\#} \mathrm{P}<0.05$ vs. berberine group.
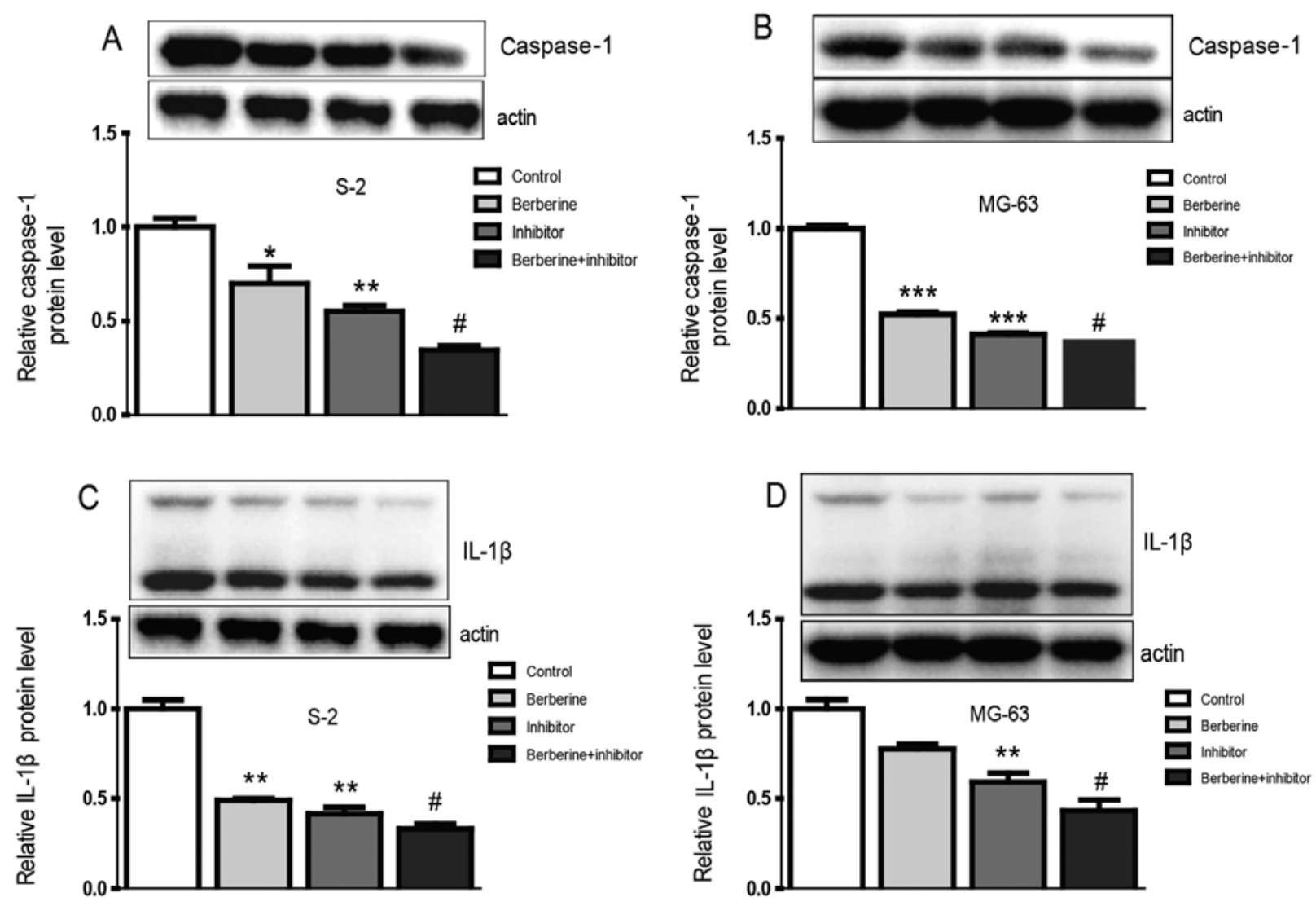

Figure 5. The effects of berberine and/or caspase- 1 inhibitor on the protein expression level of caspase- 1 and IL-1 13 . After administration of berberine ( $80 \mu \mathrm{M})$ and/or caspase-1 inhibitor for $48 \mathrm{~h}$, the protein expression level was detected by western blot analysis. (A) Caspase-1 protein expression in the Saos-2 osteosarcoma cells. (B) Caspase-1 protein expression in the MG-63 osteosarcoma cell. (C) IL-1 $\beta$ protein expression in the Saos-2 osteosarcoma cells. (D) IL-1 $\beta$ protein expression in the MG-63 osteosarcoma cells. $\beta$-actin served as an internal control. Data are expressed as mean \pm SEM. $n=3$. ${ }^{*} \mathrm{P}<0.05$ vs. control, ${ }^{* *} \mathrm{P}<0.01 \mathrm{vs}$. control, ${ }^{* * * *} \mathrm{P}<0.001$ vs. control, ${ }^{*} \mathrm{P}<0.05$ vs. berberine group. 

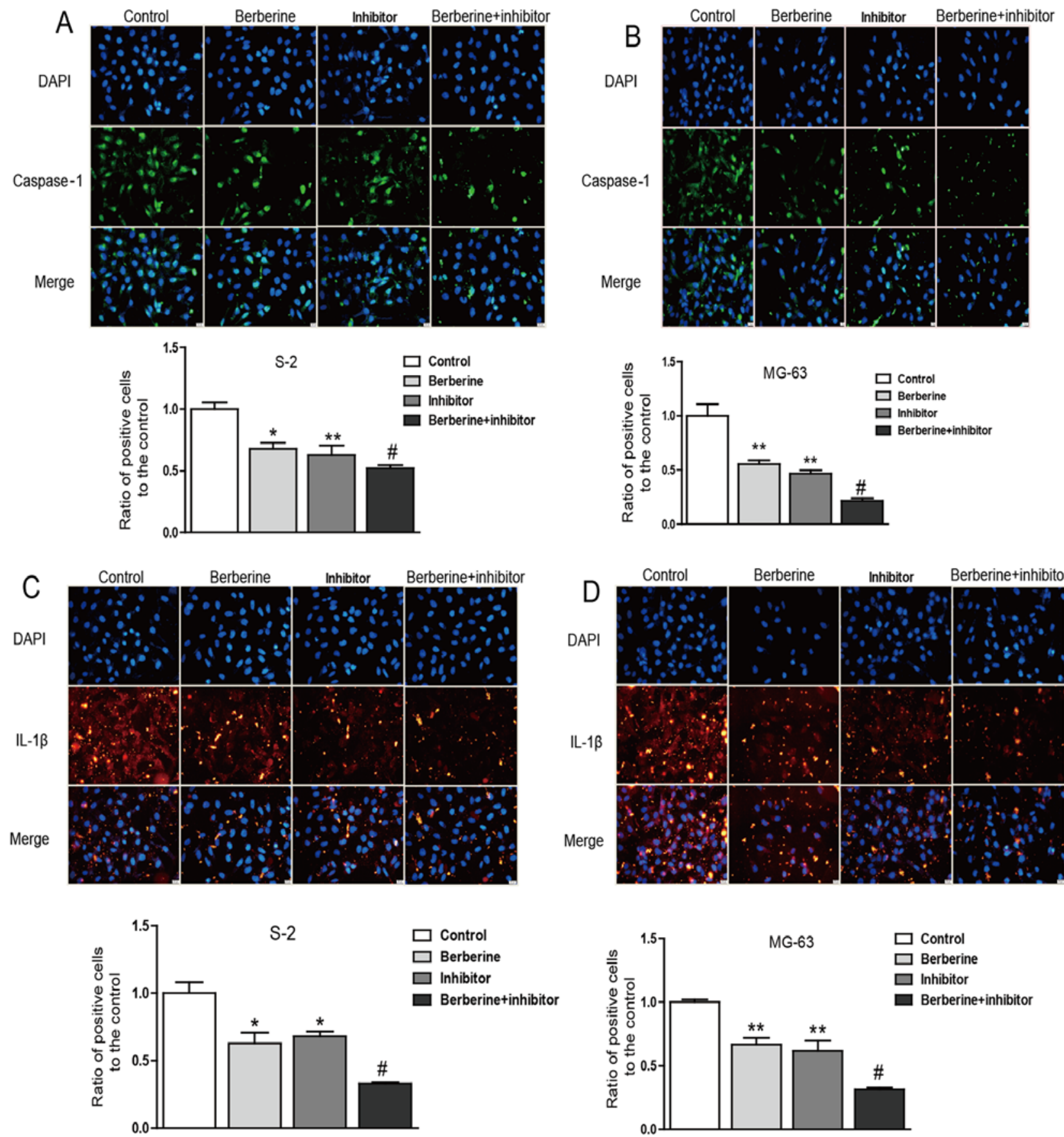

Figure 6. Berberine-induced downregulation of caspase-1 and IL-1 $\beta$ deterimined by immunofluorescence stain. (A-D) Representative images of caspase-1 and IL-1 $\beta$ immunofluorescence in osteosarcoma cells. Data are expressed as mean \pm SEM. $n=3$. ${ }^{*} \mathrm{P}<0.05$ vs. control, ${ }^{* *} \mathrm{P}<0.01$ vs. control, ${ }^{\text {" }} \mathrm{P}<0.05$ vs. berberine group.

Berberine inhibits the growth of osteosarcoma tumor in tumor-bearing mice. After eight days of post-implantation of the osteosarcoma cells, the mice were treated differently. Fig. 7 shows that the size of the osteosarcoma shrinks obviously after administration of berberine by oral gavage compared with the control group. Then, the tumor tissues were isolated for further mRNA and protein detection. The results from the tumor tissues were in accordance with the results from Saos-2 and MG-63 osteosarcoma cells (Fig. 8), which illustrate that berberine attenuates the activation of caspase-1/IL-1 $\beta$ signal pathway. In conclusion, these observations demonstrate that berberine could probably relieve the inflammation in tumor microenvironment and then results in apoptosis of osteosarcoma cells.

\section{Discussion}

Chronic inflammation occurring within the microenvironment of tumor lesions is now thought to either drive the first malignant-conferring genetic mutations and/or induce them as a result of the oncogene expression (23). It is believed that inflammation could promote the occurrence and development of tumors $(24,25)$. However, whether relieving the inflammation can attenuate the viability of cancer cells remains 


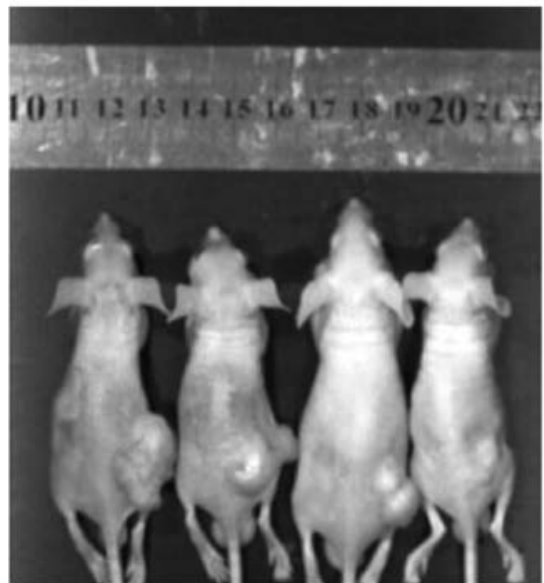

Figure 7. Berberine inhibits the growth of osteosarcoma tumors in tumorbearing mice. Tumor photographs from each treatment group. The groups in the photograph from the left to the right are as follows: control, berberine, caspase- 1 inhibitor and berberine plus caspase- 1 inhibitor. The size of the osteosarcoma shrinks obviously after the administration of berberine by oral gavage compared with the control group. The caspase-1 inhibitor exerts similar effect to berberine.

unknown. Caspases are a family of cysteine proteases that play essential roles in inflammation (18). Among the caspase family, caspase-1 is a unique protease because it activates the proinflammatory cytokines IL-1 $\beta$ and IL-18 into their active mature peptides, which play a decisive role in the formation of tumor inflammatory microenvironment and lead to a downstream inflammatory response $(26,27)$.

Over the past decades, interest in the pharmacological effects of natural bioactive compounds with respect to application in cancer treatments and for cancer prevention has greatly increased (28). Natural products represent a rich reservoir of potential small chemical molecules exhibiting various pharmacological effects. Accumulating evidence has demonstrated a dramatic correlation between the natural compounds and cancer prevention and treatment (29-31). Berberine is found in plants from the protoberberine group, such as Berberis, Berberis vulgaris and Berberis aristata. This kind of plant is traditionally used as a broad-spectrum anti-microbial medicine. During the last few decades, many studies have demonstrated that berberine has anticancer and anti-inflammatory activities. Berberine has drawn extensive attention towards its antineoplastic effects. It seems to suppress the growth of a wide variety of tumor cells, including breast cancer, lung cancer, melanoma and glioma. It has been reported that berberine induces cell circle arrest and apoptosis in human osteosarcoma cells $(17,32)$. The effects of berberine on the osteosarcoma cells have not been systematically investigated and the underlying mechanism is controversial. We tried to explain the mechanism of berberine on osteosarcoma with respect to inflammation and cancer.

In the present study, we investigated the effect of berberine on the osteosarcoma cells, and the mechanism underlying the inhibition of osteosarcoma cell viability after being treated with berberine. Based on our previous study, caspase-1 was significantly elevated in the tissues of osteosarcoma patients (Fig. 1), and the complicated relationship between inflammation and cancer, we a explored whether caspase-1/IL-1 $\beta$ was involved
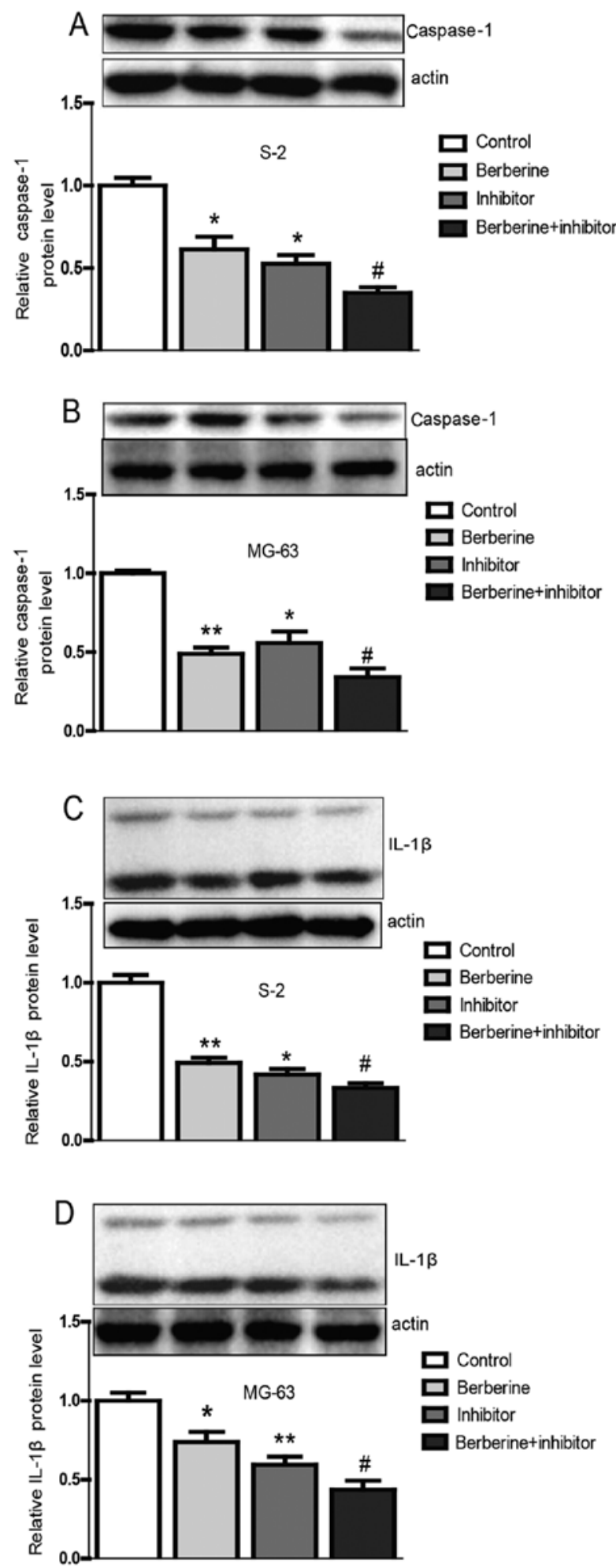

Figure 8 . Berberine inhibits the caspase-1/IL-1 $\beta$ singnaling pathway in tumor-bearing mice. (A-D) The expression level of caspase- 1 and IL- $1 \beta$ in the osteosarcoma tissues from tumor-bearing mice. The results were in accordance with the previous outcomes from the Saos-2 and MG-63 osteosarcoma cells. Berberine obviouly reduces the mRNA and the protein level of caspase- 1 and IL-1 $\beta$ compared with the control group. ${ }^{*} \mathrm{P}<0.05$ vs. control, ${ }^{* *} \mathrm{P}<0.01$ vs. control, ${ }^{\#} \mathrm{P}<0.05$ vs. berberine group.

in the molecular mechanisms underlying the anticancer property of berberine. Thus, the expression of caspase- 1 and IL-1 $\beta$ were assessed. The present results show that caspase-1 
and IL-1 $\beta$ in osteosarcoma cells were both downregulated after being treated with berberine in vivo and in vitro. These results were further confirmed by the adiministration of caspase-1 inhibitor. Caspase-1 inhibition exerts similar effect to berberine. Simultaneously, we established xenograft mouse model to further confirm the anticancer property of berberine. The results confirmed previous findings. Further studies are required to evaluate how berberine alleviates the inflammation in the tumor microenvironment causing apoptosis.

In conclusion, the present study investigated the effect of berberine on osteosarcoma cells, and the relationship between caspase-1/IL-1 $\beta$ signaling pathway and osteosarcoma cell survival implying that inflammation microenvironment could influence the viability of osteosarcoma cells to a great extent. This study suggests that caspase-1/IL- $1 \beta$ could be a new therapeutic target and berberine could be used or as an adjuvant agent in the treatment of osteosarcoma.

\section{References}

1. Sampson VB, Kamara DF and Kolb EA: Xenograft and genetically engineered mouse model systems of osteosarcoma and Ewing's sarcoma: Tumor models for cancer drug discovery. Expert Opin Drug Discov 8: 1181-1189, 2013.

2. Tabatabaei SH, Jahanshahi G and Dehghan Marvasti F: Diagnostic challenges of low-grade central osteosarcoma of jaw: A literature review. J Dent (Shiraz) 16: 62-67, 2015.

3 Li S, Sun W, Wang H, Zuo D, Hua Y and Cai Z: Research progress on the multidrug resistance mechanisms of osteosarcoma chemotherapy and reversal. Tumour Biol 36: 1329-1338, 2015.

4. Wang $Y$ and Teng JS: Increased multi-drug resistance and reduced apoptosis in osteosarcoma side population cells are crucial factors for tumor recurrence. Exp Ther Med 12: 81-86, 2016.

5. Dmitrieva OS, Shilovskiy IP, Khaitov MR and Grivennikov SI: Interleukins 1 and 6 as main mediators of inflammation and cancer. Biochemistry 81: 80-90, 2016.

6. Karin M and Greten FR: NF-kappaB: Linking inflammation and immunity to cancer development and progression. Nat Rev Immunol 5: 749-759, 2005.

7. Chen XW and Zhou SF: Inflammation, cytokines, the IL-17/ IL-6/STAT3/NF- $\kappa$ B axis, and tumorigenesis. Drug Des Devel Ther 9: 2941-2946, 2015.

8. Jearaphunt $M$, Noonin $C$, Jiravanichpaisal $P$, Nakamura $S$, Tassanakajon A, Söderhäll I and Söderhäll K: Caspase-1-like regulation of the proPO-system and role of $\mathrm{ppA}$ and caspase1-like cleaved peptides from proPO in innate immunity. PLoS Pathog 10: e1004059, 2014.

9. Ataide MA, Andrade WA, Zamboni DS, Wang D, Souza MC Franklin BS, Elian S, Martins FS, Pereira D, Reed G, et al: Malaria-induced NLRP12/NLRP3-dependent caspase-1 activation mediates inflammation and hypersensitivity to bacterial superinfection. PLoS Pathog 10: e1003885, 2014.

10. Exline MC, Justiniano S, Hollyfield JL, Berhe F, Besecker BY, Das S, Wewers MD and Sarkar A: Microvesicular caspase-1 mediates lymphocyte apoptosis in sepsis. PLoS One 9: e90968, 2014.

11. Miao EA, Rajan JV and Aderem A: Caspase-1-induced pyroptotic cell death. Immunol Rev 243: 206-214, 2011.

12. Yu D, Fu S, Cao Z, Bao M, Zhang G, Pan Y, Liu W and Zhou Q: Unraveling the novel anti-osteosarcoma function of coptisine and its mechanisms. Toxicol Lett 226: 328-336, 2014.

13. Su K, Hu P, Wang X, Kuang C, Xiang Q, Yang F, Xiang J, Zhu S, Wei L and Zhang J: Tumor suppressor berberine binds VASP to inhibit cell migration in basal-like breast cancer. Oncotarget: Jun 13, 2016. doi: 10.18632/oncotarget.9968.
14. Zhang XZ, Wang L, Liu DW, Tang GY and Zhang HY: Synergistic inhibitory effect of berberine and d-limonene on human gastric carcinoma cell line MGC803. J Med Food 17: 955-962, 2014.

15. Jin X, Yan TH, Yan L, Li Q, Wang RL, Hu ZL, Jiang YY, Sun QY and Cao YB: Design, synthesis, and anticancer activity of novel berberine derivatives prepared via CuAAC 'click' chemistry as potential anticancer agents. Drug Des Devel Ther 8: 1047-1059, 2014.

16. Zhu Y, Ma N, Li HX, Tian L, Ba YF and Hao B: Berberine induces apoptosis and DNA damage in MG-63 human osteosarcoma cells. Mol Med Rep 10: 1734-1738, 2014.

17. Liu Z, Liu Q, Xu B, Wu J, Guo C, Zhu F, Yang Q, Gao G, Gong Y and Shao C: Berberine induces p53-dependent cell cycle arrest and apoptosis of human osteosarcoma cells by inflicting DNA damage. Mutat Res 662: 75-83, 2009.

18. Man SM and Kanneganti TD: Converging roles of caspases in inflammasome activation, cell death and innate immunity. Nat Rev Immunol 16: 7-21, 2016.

19. Jin $\mathrm{Y}, \mathrm{Wu} \mathrm{W}$, Zhang W, Zhao Y, Wu Y, Ge G, Ba Y, Guo Q, Gao T, Chi X, et al: Involvement of EGF receptor signaling and NLRP12 inflammasome in fine particulate matter-induced lung inflammation in mice. Environ Toxicol: Jul 5, 2016 (Epub ahead of print) doi.org/10.1002/tox.22308.

20. Heymann D, Ory B, Blanchard F, Heymann MF, Coipeau P, Charrier C, Couillaud S, Thiery JP, Gouin F and Redini F: Enhanced tumor regression and tissue repair when zoledronic acid is combined with ifosfamide in rat osteosarcoma. Bone 37 : 74-86, 2005.

21. Sansone P and Bromberg J: Environment, inflammation, and cancer. Curr Opin Genet Dev 21: 80-85, 2011.

22. Coussens LM and Werb Z: Inflammation and cancer. Nature 420 : 860-867, 2002.

23. Mantovani A, Allavena P, Sica A and Balkwill F: Cancer-related inflammation. Nature 454: 436-444, 2008.

24. Vakkila J and Lotze MT: Inflammation and necrosis promote tumour growth. Nat Rev Immunol 4: 641-648, 2004.

25. Persidsky Y, Hill J, Zhang M, Dykstra H, Winfield M, Reichenbach NL, Potula R, Mukherjee A, Ramirez SH and Rom S: Dysfunction of brain pericytes in chronic neuroinflammation. J Cereb Blood Flow Metab 36: 794-807, 2016.

26. Cerretti DP, Kozlosky CJ, Mosley B, Nelson N, Van Ness K, Greenstreet TA, March CJ, Kronheim SR, Druck T, Cannizzaro LA, et al: Molecular cloning of the interleukin-1 beta converting enzyme. Science 256: 97-100, 1992.

27. Mariathasan S, Newton K, Monack DM, Vucic D, French DM, Lee WP, Roose-Girma M, Erickson S and Dixit VM: Differential activation of the inflammasome by caspase-1 adaptors ASC and Ipaf. Nature 430: 213-218, 2004.

28. Scott EN, Gescher AJ, Steward WP and Brown K: Development of dietary phytochemical chemopreventive agents: Biomarkers and choice of dose for early clinical trials. Cancer Prev Res (Phila) 2: 525-530, 2009.

29. Mantena SK, Sharma SD and Katiyar SK: Berberine inhibits growth, induces G1 arrest and apoptosis in human epidermoid carcinoma A431 cells by regulating Cdki-Cdk-cyclin cascade, disruption of mitochondrial membrane potential and cleavage of caspase 3 and PARP. Carcinogenesis 27: 2018-2027, 2006.

30. Katiyar SK, Meeran SM, Katiyar N and Akhtar S: p53 Cooperates berberine-induced growth inhibition and apoptosis of non-small cell human lung cancer cells in vitro and tumor xenograft growth in vivo. Mol Carcinog 48: 24-37, 2009.

31. Letasiová S, Jantová S, Miko M, Ovádeková R and Horváthová M: Effect of berberine on proliferation, biosynthesis of macromolecules, cell cycle and induction of intercalation with DNA, dsDNA damage and apoptosis in Ehrlich ascites carcinoma cells. J Pharm Pharmacol 58: 263-270, 2006.

32. Xu H, Zhao X, Liu X, Xu P, Zhang K and Lin X: Antitumor effects of traditional Chinese medicine targeting the cellular apoptotic pathway. Drug Des Devel Ther 9: 2735-2744, 2015. 